ORIGINAL ARTICLE

\title{
Client-Centeredness of Family Planning Services in a Resource Limited Setting
}

\author{
Ayinengida Walle ${ }^{1}$, Mirkuzie Woldie ${ }^{1}$
}

OPEN ACCESS

Citation: Ayinengida Walle, Mirkuzie Woldie. Client-Centeredness of Family Planning Services In a Resource Limited Setting. J Health Sci 2017;27(4):373. doi: http://dx.doi.org/10.4314/ejhs.v27i4.8 Received: February 7, 2017

Accepted: February 8, 2017

Published: July 1, 2017

Copyright: () 2017 Ayinengida Walle, et al. This is an open access article distributed under the terms of the Creative Commons Attribution License, which permits unrestricted use, distribution, and reproduction in any medium, provided the original author and source are credited.

Funding: The full financial cost of this study was covered by Jimma University Competing Interests: The authors declare that this manuscript was approved by all authors in its form and that no competing interest exists.

Affiliation and Correspondence:

${ }^{1}$ Department of Health Economics,

management and Plicy, Jimma

University, Ethiopia

*Email: aynisha5@gmail.com

\section{ABSTRACT}

BACKGROUND: Clients' needs and their satisfaction are priority issues in studying quality in reproductive health services. However, only 24-37\% of Ethiopian women were informed about the available family planning methods and their utilization. High national total fertility rate (4.8) and low contraceptive prevalence rate (29\%) might be attributed to these and other reasons. This study assessed the level of client-centeredness of family planning services and their determinants in public health facilities of Bahir Dar Town, Northwest Ethiopia.

METHODS: Exit interviews of 326 consecutively enrolled clients were conducted using structured questionnaire. Thirty consultation sessions were observed using a checklist to record client-provider interaction. The outcome variable was client centeredness as measured by perceived informed choice with perceived client-provider interaction as the intermediate variable. RESULTS: The average levels of perceived informed choice and client provider interaction were $70.0 \%$ and $67.6 \%$, respectively. Perceived clinical competence of providers, perceived integration and coordination of care, perceived accessibility of services, perceived participation of families and friends in care delivery, perceived physical comfort of the facilities and type of the health facility were the independent predictors of perceived client provider interaction. Perceived degree of client provider interaction, perceived clinical competence of providers, type of health facility and perceived accessibility of services were independent predictors of perceived informed choice $(p \leq 0.01)$.

CONCLUSION: Client-centeredness of family planning services, as measured by clien- provider interaction and informed choice was not sufficiently assured in the study facilities.

KEYWORDS: Perceived informed choice, perceived client provider interaction, client centeredness 


\section{INTRODUCTION}

The term "patient-centered medicine" was brought to the health agenda to express the belief that a patient "has to be understood as a unique human being". These days, it is already known that health services should be patient-centered. Despite this universal recognition of the need for patientcenteredness of health services, there still are different views with regard to its definition and use across different settings (1).

Several terms are being used interchangeably with patient-centered care; namely, consumercentered care, person-centered care, personalized care, family-centered care, etc. In business and management models of service delivery, the terms 'client' and 'user' are interchangeable with customer (2). Hence, the term clientcenteredness is used instead of patientcenteredness in this article. This also agrees with the fact that users of family planning services, who are the focus of this study, are not patients in most of the cases. While dealing with quality in reproductive health services, it is essential to take clients' needs and their satisfaction as a priority issue. According to a committee of family planning experts sponsored by the United States Agency for International Development (USAID), programs become more effective when they strengthen client provider interaction by treating clients well and offering respect, encouraging interaction, paying attention to verbal and nonverbal cues and using handouts to reinforce key messages (3).

Client-centered family planning service is one which enables clients to choose a method they want, continue using it and return when they need help or change the method. To achieve these, clients' needs and preferences should guide the planning and implementation of family planning services. To this end, client-provider communication is at the center of clientcentered family planning services (4).

After the 1994 International Conference on Population and Development in Cairo, the paradigm on family planning shifted to providing client-centered services. The frequently quoted way of delivering client-centered approach is providing clients and potential clients better information (5). However, only $24 \%-37 \%$ of Ethiopian women were informed about possible side effects of the family planning method they were using, actions they should take if they experience side effects and other family planning methods available (6). A study from the southwestern part of Ethiopia reported that only $9.3 \%$ of new clients made informed choices with only $31.3 \%$ being told about choices of more than one method (7).

The consequence of these problems is reflected by the national total fertility rate (4.8) and contraceptive prevalence rate $(29 \%)$. The unmet need for family planning among married women is found to be $25 \%$. This figure is even higher (33\%) among those aged 15-19 years (8).

Generally, despite the presence of these and some other studies conducted in Ethiopia measuring the quality of family planning services, they failed to measure a critical dimension of quality, client-centeredness $(6,7,9$, 10,11). Moreover, most of these studies did not report what factors are affecting client- provider interaction and informed decision making in family planning (FP) services. Hence, this study aimed to assess the level of client-centeredness of family planning services and associated factors in some selected public health facilities of Bahir Dar Town, Northwest Ethiopia, in March 2013. The questions we posed to do so were:

What is the degree of perceived clientcenteredness in delivery of FP services in public health facilities of the Town?

What factors predict the degree of perceived client-centeredness in the delivery of FP services?

\section{METHODS AND MATERIALS}

Context and setting of the study: The study was conducted from 11-30 March, 2013, in Bahir Dar Town which is located at $565 \mathrm{Km}$ North west of Addis Ababa, the capital city of Ethiopia. The town had a total of 274,826 populations. One referral hospital and seven health centers(HCs) made up the public health facilities in the town. All of these facilities 
provide family planning services and were supported by community based service delivery including health information provision by urban health extension professionals. There were also private health facilities and non-governmental organizations which provide these services. This study was conducted in selected health facilities including the only available public hospital which was included purposively, one from the two newly built HCs (Shum Abo) and three from the remaining five $\mathrm{HCs}$ (Abay, Han and Bahir Dar).

Study design: Facility based cross sectional study design was employed where by all the data were collected in a health facility setting reflecting the situation of the health facilities within a short time (11-30 March, 2013).

Population : The only public hospital and four of the seven (randomly selected) health centers in the town were included in this study. The data sources for the study were a sample of female family planning users who visited the facilities during the data collection period.

Sample size determination and sampling technique: A sample of 326 clients, calculated using single population proportion formula, was taken. The assumptions for the calculation of this sample were, $\mathrm{P}=74 \%$ (Proportion of clients made choice of the method themselves with the help of the provider,2005)(11), level of significance $(\alpha)=0.05 \quad(5 \%)$, and Margin of error (d) $=0.05(5 \%)$.

The total sample was allocated to the selected health facilities proportionally by considering

Percentage of maximum scale score

$$
=\frac{\text { actual score }- \text { potential minimum score }}{\text { potential maximum score }- \text { potential minimum score }} * 100
$$

Instrument and data collection procedure: After a thorough review of literatures $(13,14$, $15,16,17)$, a structured questionnaire was developed to assess socio-demographic variables, experience of clients at the health facility and perception of clients about service providers. Except the questions for socio-demographic variables, all others were Likert scale types. The clients' flow to the selected health facilities. Then, clients were enrolled in the study consecutively. Moreover, 30 consultation sessions (about $10 \%$ of the sample for client exit interview) and the service areas in the facilities were observed. The samples for client provider communication observation were also allocated proportional to the sample allocated for the client exit interview from each health facility.

Study variables: The main outcome variable, client-centeredness, was measured by two proxy indicators; namely, perceived informed choice as an outcome variable and perceived clientprovider communication as an intermediate variable.

Informed choice: Six items of a Likert scale type ranging from strongly disagree to strongly agree (1-5) was used to measure this variable. Factor analysis was employed to generate factor scores to be used for further analysis. The resulting factor scores were named as perceived informed choice score. The level of informed choice was measured by the mean of the percentage of maximum scale scores. Informed decision and informed choice are used as synonyms in this article.

Client provider interaction/communication: Like Informed choice, seven items with five point Likert scale were used to measure this intermediate variable. Factor scores (perceived client provider communication score) were generated using factor analysis and the level of client provider communication was measured by the mean of the percentage of maximum scale scores of each individual. collection. Data were collected through exit interview of female family planning service users. The consultation sessions were observed using semi-structured observation check list that addressed the GATHER (Ggreeting the client, Asking and recording of relevant information, Telling the clients the information that can help them to decide, Helping them to choose 
a method, Explaining and Return) approach. The facilities' environments (managers' rooms, patients' waiting areas of all units, FP units and youth friendly clinics) were also observed for supplementary information like the presence of IEC materials and posted plans of the FP unit.

Data processing and analysis: Data were entered into computer software (SPSS 20.0, IBM Corporation) and cleaned for inconsistencies and missing values. Descriptive statistical measures such as frequency, percentages and measures of central tendency were generated. To measure the internal consistency of the items in the different Likert scale types, Cronbach's Alpha value was generated and the values ranged from $50.9 \%$ to $77.3 \%$. For the scales with Cronbach's Alpha value of less than $70 \%$, item(s) were deleted if doing so increased the Cronbach's Alpha coefficient.

Factors were extracted using principal components method of extraction, using Eigen values of 1 or above and varimax method of rotation with Kaiser Meyer normalization. Items that have weak loading (Item loading <0.4) and items that loadon more than two factors were discarded. The generated factor scores were used in subsequent analysis.

To assess the relation between the dependent and independent variables, Pearson correlation, ANOVA and independent samples $t$ test were used. Variables found to be significant in these models, taking p-value of less than or equal to 0.1 , were taken to multiple linear regression. Finally, the variables that were statistically significant in the final fit model ( $p$ values of less than or equal to 0.05 ) were taken as independent predictors of informed choice and client-provider communication. In the regression analysis, stepwise method of selection was used and all the assumptions of the specified statistical analysis methods were checked.

\section{RESULTS}

Characteristics of respondents: Three hundred eleven family planning users were involved in the study . The mean age of the respondents was 24.6 (+5.5) years. Approximately, one-third of the clients were illiterate $(31.8 \%)$. Thirty nine (12.5\%)of them never used FP services before. One hundred seventy seven $(56.9 \%)$ of them have hade birth before. (Table 1).

Perceived informed choice: The item loadings ranged from 0.61 to 0.75 , the total variance accounted for the factor was $47.8 \%$ and the Cronbach's alpha was $72.1 \%$ with a standard deviation of 17.1 .

The mean of perceived informed choice score was $70.0 \%$ (range: $25.0 \%$ to $100.0 \%$ ).

Findings from the observations revealed that information on the available FP methods was given for 17 of the $30(56.7 \%)$ clients. The advantage and disadvantages of the methods were explained to $13(43.3 \%)$ clients while only $10(33.3 \%)$ clients were informed about possible side effects. Information Education and Communication (IEC) materials were used only in $2(6.7 \%)$ of the consultations observed. In the majority of the consultations, providers were inclining to convincing the clients to choose long acting family planning methods (LAFP), especially implants. In effect, the discussions between the clients and the providers were focused on implants as compared to pills and injectables. The idea of dual protection was mentioned only in 2(6.7\%) of the sessions. Explanations about the method chosen were given to one-fourth of the clients. The explanations were on side effects, how to take the pills for pills users and the possibility of coming back for any inconveniences.

Perceived client provider communication: Through factor analysis, one factor was extracted with all the seven items loaded on it ranging from 0.44 to 0.74 . The total variance accounted for the factor and the Cronbach's Alpha for the items were $41.2 \%$ and $75.4 \%$, respectively. 
Table 1: The characteristics of clients, Bahir Dar town, Northern West Ethiopia, March 2013.

\begin{tabular}{|c|c|}
\hline Variables & n $(\%)$ \\
\hline \multicolumn{2}{|l|}{ Health facilities name } \\
\hline Han $\mathrm{HC}$ & $99(31.8)$ \\
\hline Bahir Dar HC & $79(25.4)$ \\
\hline Abay HC & $79(25.4)$ \\
\hline Felegehiwot Referral Hospital & $42(13.5)$ \\
\hline Shum Abo HC & $12(3.9)$ \\
\hline \multicolumn{2}{|l|}{ Educational status } \\
\hline Illiterate & $99(31.8)$ \\
\hline Attend primary school & $81(26.0)$ \\
\hline Attend secondary school & $65(20.9)$ \\
\hline College and above & $51(16.4)$ \\
\hline Can read and write & $15(4.8)$ \\
\hline \multicolumn{2}{|l|}{ Marital status } \\
\hline Married & $253(81.4$ \\
\hline Single/boy friend & $48(15.4)$ \\
\hline Divorced/separated & $10(3.2$ \\
\hline Widowed & $0(0)$ \\
\hline \multicolumn{2}{|l|}{ Religion } \\
\hline Orthodox & 289(92.9) \\
\hline Muslim & $16(5.1)$ \\
\hline Others & $6(1.9)$ \\
\hline \multicolumn{2}{|l|}{ Occupation } \\
\hline House wife & $98(31.5)$ \\
\hline Others & $86(27.7)$ \\
\hline Merchant & $37(11.9)$ \\
\hline Student & $30(9.6)$ \\
\hline NGO employee & $22(7.1)$ \\
\hline Government employee & $21(6.8)$ \\
\hline Farmer & $17(5.5)$ \\
\hline \multicolumn{2}{|l|}{ Number of children born } \\
\hline 1 & $84(47.5)$ \\
\hline $2-5$ & $92(52)$ \\
\hline$>5$ & $1(0.5)$ \\
\hline \multicolumn{2}{|c|}{ Number of children living today for mothers with two or more children } \\
\hline One & $4(4.3)$ \\
\hline Two & $47(50.5)$ \\
\hline Three & $25(26.9)$ \\
\hline Four or more & $17(18.3)$ \\
\hline \multicolumn{2}{|l|}{$\sum$ FP methods used in the past } \\
\hline Injectables & 212(77.9) \\
\hline Pills & $29(10.7)$ \\
\hline Implants & $28(10.3)$ \\
\hline Others & $3(1.1)$ \\
\hline \multicolumn{2}{|l|}{ FP methods clients are using currently } \\
\hline Injectables & $222(71.4)$ \\
\hline Implants & $58(18.6)$ \\
\hline Pills & $22(7.1)$ \\
\hline Condom & $1(0.3)$ \\
\hline
\end{tabular}

Note:- $\sum$ others included Condom and IUCD

DOI: http://dx.doi.org/10.4314/ejhs.v27i4.8 
The mean of perceived client-provider communication score was $67.6 \%$ with a standard deviation of 16.9 .

During the observation of the clientprovider interaction, it was found that $22(73.3 \%)$ clients were offered a seat, 4(13.3\%) clients were warmly welcomed and 6(20\%) were asked their names. Twenty-three (76.7\%) clients were asked about their reasons to visit while medical history was inquired only for 2(6.7\%) of the clients. Among the repeat clients, 15(40.5\%) were asked about any intention of changing the method they were using and 10(33.3\%) clients were requested to report any side effects encountered sofar. It was observed that there was no direct eye contact between the client and the provider in about one-third of the consultation sessions.

Table 2: Perceived Informed choice and Client- Provider communication scores, Bahir Dar town, Northern West Ethiopia, March 2013

\section{$\begin{array}{lll}\text { Category of Health facility } & \text { Informed Choice } & \text { Client-Provider Communication }\end{array}$}

\begin{tabular}{lcccc}
\cline { 2 - 5 } & Mean & SD & Mean & SD \\
\hline Felegehiwot Referral Hospital & 58.5 & 15.59 & 56.9 & 13.92 \\
Han Health Center & 74.2 & 10.96 & 69.4 & 12.36 \\
Bahir Dar Health Center & 79.3 & 15.39 & 76.1 & 16.80 \\
Abay Health Center & 61.3 & 18.57 & 61.5 & 18.96 \\
Shumabo Health Center & 70.4 & 17.24 & 73.5 & 9.57 \\
\hline
\end{tabular}

Provider related factors: Factor analysis for provider related variables revealed acceptable loading of all items $(\geq 0.4)$ on the respective factors extracted (Table 3 ). With regard to the sex of providers, $229(73.6 \%)$ of the clients received services from female providers.

Table 3: Descriptions of factor analysis outputs to measure provider related factors, Bahir Dar town, North West Ethiopia, March 2013.

\begin{tabular}{|c|c|c|c|c|c|}
\hline \multirow[b]{2}{*}{ Scales } & \multicolumn{3}{|c|}{ Feature Descriptions } & \multirow[b]{2}{*}{$\begin{array}{l}\text { Range of } \\
\text { item } \\
\text { loadings }\end{array}$} & \multirow[b]{2}{*}{$\begin{array}{l}\text { Cronbach's } \\
\text { Alpha }\end{array}$} \\
\hline & $\begin{array}{l}\text { Number } \\
\text { of items } \\
\text { used }\end{array}$ & $\begin{array}{l}\text { Number of } \\
\text { factors } \\
\text { extracted }\end{array}$ & $\begin{array}{l}\text { Total variance } \\
\text { accounted for }\end{array}$ & & \\
\hline $\begin{array}{l}\text { Perceived courtesy, respect } \\
\text { and empathy }\end{array}$ & 3 & 1 & $69 \%$ & $0.79-0.85$ & $77.3 \%$ \\
\hline Perceived Emotional support & 2 & 1 & $69.6 \%$ & Both 0.83 & $56.4 \%$ \\
\hline Perceived clinical competence & 4 & 1 & $52.85 \%$ & $0.63-0.80$ & $69.8 \%$ \\
\hline $\begin{array}{l}\text { Perceived Non verbal } \\
\text { communication }\end{array}$ & 5 & 1 & $63.1 \%$ & $0.61-0.81$ & $78.1 \%$ \\
\hline
\end{tabular}

Facility related factors: Perceived accessibility of care was measured with a single item of the five point Likert scale. For this item, 191(61.4\%) clients strongly agreed, 69(22.2\%) just agreed, $31(10.0 \%)$ were neutral while16 $(5.1 \%)$ disagreed and $4(1.3 \%)$ strongly disagreed.
For each of the remaining five variables one factor was extracted with acceptable range of chronbach's Alpha and Item loading. With regard to facility related factors, the findings from the observation showed that annual plans were posted at least in one of the consultation rooms for all facilities, except for the hospital. In all of the

DOI: http://dx.doi.org/10.4314/ejhs.v27i4.8 
facilities, posters advertizing FP services were posted at least in two places inside the facility.

However, only two types of posters were posted in all of the facilities repeatedly. It was noted that posters advertizing in favor of a particular FP method were posted in Han HC. In Bahir Dar HC FP Clinic, the rights of clients (information, access, privacy and confidentiality, continuity, choice, safety, dignity, opinion and comfort) were posted on A4 size paper in English language.

Predictors of client-provider interaction (CPI): Multiple linear regression with stepwise method of selection, the final model, revealed that perceived clinical competence of providers, perceived integration and coordination of care, perceived accessibility of care, perceived participation of family and friends in care delivery, perceived physical comfort of the facilities and the health facility were the final independent predictors of CPI $(\mathrm{F}(6,304)=32.040$ $\mathrm{p} \leq 0.01)$. The model explained $38.7 \%$ of the variability in perceived client-provider interaction score (unadjusted $\mathrm{R}^{2}=38.7 \%$ ).
Hence, a unit increase in the score of perceived clinical competence of providers would result in 0.313 units increase in the score of perceived client-provider interaction $(B=0.313$, 95\%CI: 0.253, 0.454). When the score of perceived integration and coordination of care changed by one unit, the perceived clientprovider interaction score would change by $0.149 \quad(\mathrm{~B}=0.149, \quad 95 \% \mathrm{CI}: \quad 0.041,0.251)$. Moreover, clients who agreed on the accessibility of services had a 0.375 unit less perceived clientprovider interaction score than those who strongly agreed on accessibility of services $(B=$ $-0.375,95 \%$ CI: $-0.594,-0.156)$. Clients in Bahir Dar Health Center had 0.267 unit higher perceived CPI scores than those who were from Felegehiwot Referral Hospital $(\mathrm{B}=0.267,95 \% \mathrm{CI}: \quad 0.040,0.493)$. When the perceived participation of family and friends increased by one unit, the perceived CPI score would increase by 0.147 units $(B=0,147,95 \% \mathrm{CI}$ : $0.050,0.244)$. A unit change in the score of the perceived physical comfort of facility would induce 0.139 unit change in perceived CPI score $(B=0.139,95 \% \mathrm{CI}: \quad 0.042 . \quad 0.236)$.

Table 4:- Independent predictors of client provider interaction among family planning service users in public health facilities of Bahir Dar town, North West Ethiopia, March 2013

\begin{tabular}{|c|c|c|c|c|c|c|}
\hline \multirow{3}{*}{ Predictors } & \multirow{2}{*}{\multicolumn{2}{|c|}{$\begin{array}{l}\text { Unstandardized } \\
\text { Coefficient }\end{array}$}} & \multirow{3}{*}{$\begin{array}{l}\text { Standardized } \\
\text { coefficient } \\
\text { B }\end{array}$} & \multirow{3}{*}{ Sig } & \multicolumn{2}{|c|}{$95.0 \%$ Cifor B } \\
\hline & & & & & \multirow{2}{*}{$\begin{array}{l}\text { Lower } \\
\text { bound }\end{array}$} & \multirow{2}{*}{$\begin{array}{l}\text { Upper } \\
\text { bound }\end{array}$} \\
\hline & $\mathrm{B}$ & Std.Error & & & & \\
\hline Constant & 0.15 & 0.59 & & 0.797 & -0.102 & 0.132 \\
\hline $\begin{array}{l}\text { Perceived clinical competence of } \\
\text { providers }\end{array}$ & 0.313 & 0.053 & 0.313 & 0.000 & 0.209 & 0.416 \\
\hline $\begin{array}{l}\text { Perceived integration and } \\
\text { coordination of care }\end{array}$ & 0.149 & 0.055 & 0.149 & 0.007 & 0.041 & 0.257 \\
\hline $\begin{array}{l}¥ \text { Perceived accessibility of care } \\
\text { (agreement on less amount of cost }\end{array}$ & & & & & & \\
\hline $\begin{array}{l}\text { the client incurred to get services) } \\
\text { Agree }\end{array}$ & -0.375 & 0.111 & -0.156 & 0.001 & -0.594 & -0.156 \\
\hline $\begin{array}{l}\text { Perceived participation of family and } \\
\text { friends in care delivery }\end{array}$ & 0.147 & 0.049 & 0.147 & 0.003 & 0.050 & 0.244 \\
\hline Physical comfort of the facility & 0.139 & 0.049 & 0.139 & 0.005 & 0.042 & 0.236 \\
\hline тм Health facility & 0.267 & 0.116 & 0.117 & 0.021 & 0.040 & 0.493 \\
\hline
\end{tabular}

Note:-The reference category for $¥$ is strongly agree on incurring less cost to get services and that of ${ }^{\mathrm{TM}}$ is

Felegehiwot referral hospital

DOI: http://dx.doi.org/10.4314/ejhs.v27i4.8 
In the model, the perceived clinical competence and perceived integration and coordination of care alone explained $30.6 \%$ of the overall variance in perceived client-provider interaction score, which was $79.1 \%$ of the variance explained by the overall model. Table 4 shows the final predictors of client-provider interaction.

Table 5: Independent predictors of informed choice among family planning service users in public health facilities of Bahir Dar town, North West Ethiopia, March 2013

\begin{tabular}{|c|c|c|c|c|c|c|}
\hline \multirow{3}{*}{ Predictors } & \multirow{2}{*}{\multicolumn{2}{|c|}{$\begin{array}{l}\text { Unstandardized } \\
\text { Coefficient }\end{array}$}} & \multirow{3}{*}{$\begin{array}{l}\text { Standardized } \\
\text { coefficient }\end{array}$} & \multirow{3}{*}{ Sig } & \multicolumn{2}{|c|}{$95.0 \%$ CI for B } \\
\hline & & & & & \multirow{2}{*}{$\begin{array}{l}\text { Lower } \\
\text { bound }\end{array}$} & \multirow{2}{*}{$\begin{array}{l}\text { Upper } \\
\text { bound }\end{array}$} \\
\hline & B & Std. Error & & & & \\
\hline Constant & -0.015 & 0.081 & & 0.835 & -0.175 & 0.145 \\
\hline Perceived client provider interaction & 0.408 & 0.048 & 0.408 & 0.000 & 0.313 & 0.503 \\
\hline $\begin{array}{l}\text { Perceived clinical competence of } \\
\text { providers }\end{array}$ & 0.187 & 0.048 & 0.187 & 0.000 & 0.093 & 0.281 \\
\hline \multicolumn{7}{|l|}{ (B) Accessibility of care } \\
\hline Agree & -0.521 & 0.111 & -0.217 & 0.000 & -0.739 & -0.303 \\
\hline Neutral & -0.424 & 0.143 & -0.127 & 0.003 & -0.705 & -0.143 \\
\hline \multicolumn{7}{|l|}{${ }^{\mathrm{TM}}$ Health facility } \\
\hline Bahir Dar HC & 0.339 & 0.113 & 0.148 & 0.003 & 0.116 & 0.561 \\
\hline Han HC & 0.273 & 0.105 & 0.127 & 0.010 & 0.066 & 0.480 \\
\hline
\end{tabular}

NOTE: The reference category for ${ }^{\circledR}$ is strongly agree and that of TM is Felegehiwot referral hospital

Predictors of informed choice: In the initial models, health facility, marital status of the client, perceived accessibility of care, perceived clientprovider interaction, perceived courtesy respect and empathy of providers, perceived emotional support given by providers, perceived clinical competence of providers, perceived nonverbal communication of the provider, perceived integration and coordination of care, perceived participation of families and friends in care delivery, perceived information, education and communication, perceived physical comfort of the facilities and perceived commitment of leadership were significant variables. By the final fit model, perceived CPI, perceived clinical competence of providers, the health facilities and perceived accessibility of care were identified as final independent predictors of informed choice. The final model was significant enough to explain perceived informed choice $(\mathrm{F}(6,304)=55.201, \mathrm{p}<0.01)$; it explained $52.1 \%$ of the variability in perceived informed choice score $\left(\mathrm{R}^{2}=0.521\right)$.

A unit change in perceived CPI score would result in 0.408 units change in the perceived informed choice score of the clients. Perceived client-provider interaction alone explained 39.7\% of the variability in perceived informed choice score. Clients in Bahir Dar and Han health centers had 0.339 and 0.273 higher informed choice scores compared with clients from Felegehiwot Referral Hospital, respectively. Those who agreed and were neutral on the accessibility of care had 0.521 and 0.424 lower informed choice scores than those who strongly agreed. When perceived clinical competence of providers increased by one unit, the perceived informed choice score would increase by 0.187 units (Table $5)$.

\section{DISCUSSION}

In this study, the average level of clientcenteredness of FP services as measured by informed decision making was found to be $70 \%$. The average level in terms of the intermediate variable (clientprovider interaction) was $67.6 \%$. These figures indicate that client centeredness in the delivery of FP services was not fully assured in the public health facilities of Bahir Dar Town.

Observations of the client-provider communication sessions revealed that only two consultation sessions were supported by IEC materials, there was poor

DOI: http://dx.doi.org/10.4314/ejhs.v27i4.8 
direct eye contact and providers inclined to promoting the use of implants. The discussion more emphasized the advantage of implants over pills and injectables. In the majority of the interactions, providers were trying to convince clients to use LAFP methods specially implant. The idea of dual protections was raised in only two CPI (6.7\%) sessions. Moreover, observations of facility environments showed that the posters put up in the health facilities were only of two types and their contents were in favor of long acting family planning methods (LAFP).This was also evidenced by the switching of the majority of pill users (25 out of 29 clients $=86.2 \%$ ) and all of the condom and IUD users to injectables and implants at the time of data collection. From these findings, one could understand that clients might not get enough information to make informed decisions. Similarly, a study from Kenya reported that informed choice was not assured fully due to the insufficiency of information given to clients (17).

Perceived level of client-provider interaction was significantly different across the public health facilities with the maximum and minimum scores observed in Bahir Dar HC (76.1\%) and Felegehiwot Heferral Hospital (56.9\%), respectively. Clients in Bahir Dar and Han health centers had 0.339 and 0.273 higher informed choice scores compared with clients from Felegehiwot Heferral Hospital, respectively. This was also supported by findings from observation. Because in Bahir Dar Health Center, it was observed that clients' rights (as clients have the rights of information access, privacy and confidentiality, continuity, choice, safety, dignity, opinion and comfort) were posted with on A4 size paper inside the FP clinic, even if it was in English. Moreover, in the facility's Youth Friendly Clinic, a chart (advertizing the available methods, their advantages and disadvantages, how to take and other related information) was posted. However, an earlier study from Nigeria reported that quality of client-provider interaction in delivering FP services was similar across health facilities (12). This difference might be due to nonuniform standards of care in services delivery. The average levels of perceived client providerinteraction in Abay Health Center and Felegehiwot Referral Hospital were less than the overall average. The following two possible explanations might be plausible for this. First, many clients from Abay HC were from the rural villages so that they might not communicate their feelings well. However, clients from Felegehiwot Referral Hospital were being told to get the services from the health centers nearby their villages, as witnessed by observation, which might lead them to have negative impression. This is because some clients from the hospital were clients who came for other services besides FP.

Perceived clinical competence and perceived integration and coordination of care alone explained $30.6 \%$ of the overall variance in clientprovider interaction score, which is $79.1 \%$ of the variance explained by the overall model. This is supported by what was reported by Program for Appropriate Technology in Health (PATH), 1999. According to this report, training is the base for improving CPI (4). This in fact supports our findings since both clinical competence and integration and coordination of care are yielding to training efforts.

Perceived client-provider interaction and perceived clinical competence of providers were the most significant predictors of informed decision making. A unit change in CPI score would result in 0.408 units change in the informed choice score, and it alone explained $39.7 \%$ of the variability in informed choice. This is in line with PATH's report of 1999. According to the report, CPI was the most significant attribute of family planning services that affects not only informed choice but also overall quality of reproductive health (4).

In conclusion, client-centeredness of family planning services, as measured by client -provider interaction and informed choice, was not fully assured. There were significant differences across the public health facilities of Bahir Dar Town in the level of client-centeredness of care. Perceived clinical competence of providers and perceived integration and coordination of care explained the majority of the variations in the level of clientprovider interaction. Client-provider interaction is the most important independent predictor of informed choice among FP clients. Perceived clinical competence of providers, perceived accessibility of care and the health facilities themselves were confounding factors of CPI in predicting informed choice. 
Health care providers and managers of FP services, including those in resource limited settings, can draw several lessons from the findings reported in this article. The quality of client-provider communication/interaction, as perceived by clients, is a key to ensuring informed decision making in the delivery of FP services. Need-based trainings targeting clinical competence, integration and coordination of care and communication skills are all critical measures to improve patient-centeredness in the provision of FP services.

The findings of this study need to be read taking note of the following limitations. Since exit interviews were done inside the facilities, there might be social desirability bias. Due to the disguised nature of observations of clientprovider interactions Hawthorne effect might occur. Since consecutive sampling was done to identify clients for exit interview, there is a possibility of selection bias.

\section{REFERENCES}

1. Mary CB, Somnath S, and Lisa AC. The role and relationship of cultural competence and patient-centeredness in health care quality. October 2006.

2. Australian commission on safety and quality in health care. Patient-centered care: Improving quality and safety by focusing care on patients and consumers, Discussion paper draft for public consultation. September 2010.

3. Program for appropriate technology in health (PATH). Improving Interactions with Clients: A key to high-quality services. July 1999 avaialable at https://www.path.org/publications/files/eol17_2. pdf.

4. K4Health. Client-centered-family-planning-care, released by Knowledge for Health, Johns Hopkins Bloomberg School of Public Health's center for communication programms (JHU.CCP). Accessed on June 05, 2013 at http://www.k4health.org/.

5. Marilou C, Marlina L,Saumya RR, and Anrudh J. A client-centered approach to family planning: The davao project. Studies in family planning. 2001; 32(4):302-314.

6. Ethiopia Central Statistical Agency and ICF International. 2011 Ethiopia Demographic and
Health Survey: Key Findings. Calverton, Maryland, USA: 2012.

7. Eskindir L, Makonnen A, Chali J, Fasil T. Assessment of quality of care in family planning services in jimma zone, southwest Ethiopia. Ethiop.J.Health Dev. 2004;18(1):8-18.

8. United states agency for international development (USAID) and Federal ministry of health (FMOH), Family Planning in Ethiopia, August 2012.

9. Getnet M, Amy T, Abiy S, et al. Quality of Family Planning Service in the Health Facilities of East Shoa Zone, Oromia Regional State, Ethiopia, 2008

10. Tigist GE and Yilma M. Quality of reproductive health services at private forprofit institutions in Addis Ababa. Ethiopian Journal of Reproductive Health, 2008; 2(1):35.

11. Mesganaw F. Quality of family planning services in northwest Ethiopia, Ethiop.J.Health Dev. 2005;19(3):195-202.

12. Mohammed J S, Lasiele AY, Aishat OS. Counseling and Client Provider-Interactions as Related To Family Planning Services in Nigeria. Journal of Education and Practice, 2012; 3(5):16-23.

13. Dale S. Patient-centered care: What does it take?. Picker institute and the common Wealth fund; April 2007.

14. International alliance of patients' organizations (IAPO).What is patient centered health care? A review of definitions and principles; 2007.

15. Nicola M, Peter B. Patient-centeredness: a conceptual framework and review of the empirical literature. Social Science \& Medicine; 2000;51:1087-1110.

16. Ravishankar J and Sumedha C. Patient Centered Care - A Conceptual Model and Review of the State of the Art. The Open Health Services and Policy Journal 2011; 4: 15-25.

17. Young MK, Adrienne $\mathrm{K}$ and Stephen $\mathrm{M}$. Informed Choice and Decision-Making In Family Planning Counseling in Kenya. International family planning perspectives. March 1998; 24(1):4-11\&42. 